\title{
INCIDENCE OF RENAL ACIDIFICATION DEFECT IN UROLITHIASIS AS MEASURED BY AMMONIUM CHLORIDE LOADING TEST
}

\author{
Prakash Chandra Sahlot ${ }^{1}$
}

${ }^{1}$ Assistant Professor, Department of General Surgery, AIIMS, Udaipur, Rajasthan.

\begin{tabular}{l}
\hline ABSTRACT \\
BACKGROUND \\
Urinary calculus is well known from ancient times and prevalent in several pockets of India and in Rajasthan also. The \\
involvement of parathyroid hormone and renal tubular acidification defect in calculogenesis have not yet investigated properly in \\
these particular region.
\end{tabular}

\section{MATERIALS AND METHODS}

The present study was planned with the following two objectives in view (a)-To study the incidence of Renal Tubular Acidification (RTA) defects and Hyperparathyroidism (HPT) in the local stone formers by using the short ammonium chloride loading test; and (b) To establish the adequate dose of ammonium chloride for the test. For the present study, patient of urinary calculous radio-opaque shadow were taken from AIIMS surgical ward and result compared with normal subject.

\section{RESULTS}

It was evident that $75 \mathrm{mg}$ per $\mathrm{kg}$ body weight $\mathrm{NH}_{4} \mathrm{CL}$ is inadequate dose, as only $50 \%$ of normal subject achieve pH up to 4.5 as compared of $100 \%$ on $150 \mathrm{mg}$ per kg body weight of $\mathrm{NH}_{4} \mathrm{CL}$. After adequate challenge $(150 \mathrm{mg}$ ammonium chloride per kg body weight), all normal subject achieve $\mathrm{pH} 4.5$, whereas in stone former only $46.2 \%$ could lower pH between 4.6 to 5 and $53.8 \%$ could not lower it below 5. This observation suggested the presence of incomplete RTA defect in 53.8\% of stone formers. None of the subject excreted alkaline urine indicating absence of complete RTA defect. Ammonium chloride loading causes increased urinary calcium excretion in stone former as well as in normal subject no significant difference was observed and did not show any evidence of hyperparathyroidism in the subjects investigated.

\section{CONCLUSION}

Incomplete RTA defect present in 53.8\% of stone formers investigated. Complete RTA defect not present in any stone formers. Hyperparathyroidism was not present in any of the subject. Short ammonium chloride loading test is a reliable tool to evaluate the presence of hyperparathyroid's and Renal Tubular Defect (RTA defect). For proper result, $150 \mathrm{mg} / \mathrm{kg}$ body weight ammonium chloride is adequate dose.

\section{KEYWORDS}

Renal Tubular Acidification [RTA] Defect [Complete and Incomplete], Hyperparathyroidism, Urinary Calculus Disease

HOW TO CITE THIS ARTICLE: Sahlot PC. Incidence of renal acidification defect in urolithiasis as measured by ammonium chloride loading test. J. Evolution Med. Dent. Sci. 2016;5(81):6070-6074, DOI: 10.14260/jemds/2016/1371

\section{INTRODUCTION}

Urinary calculus is well known from ancient times and prevalent in several pockets of India including Rajasthan and recurrence is also another disquieting feature. The involvement of parathyroid hormone and renal tubular acidification defect in calculogenesis has not yet investigated properly. As it has been stressed that hyperthyroidism must be considered in every patient presenting with renal tract stone or nephrocalcinosis and even in the cases of renal colic. Hyperparathyroidism is directly proportional to nephrocalcinosis, but measurement of H. P. T. is costly. So short ammonium chloride loading test is to ascertain parathyroid status is relatively less cumbersome and requires a very simple technique. Incidentally, this test can also be used as a diagnostic aid in renal tubular acidification

Financial or Other, Competing Interest: None.

Submission 21-05-2016, Peer Review 27-09-2016,

Acceptance 03-10-2016, Published 10-10-2016.

Corresponding Author:

Dr. Prakash Chandra Sahlot,

\#15, Pratap Ji Ki Badi Ambamata,

Udaipur-313001, Rajasthan.

E-mail:pcs9111950@gmail.com

DOI: $10.14260 /$ jemds $/ 2016 / 1371$ acidification defect resulting in the failure of renal tubules to secrete $\mathrm{H}+$, which is often associated with failure to produce $\mathrm{NH} \mathrm{4+} \mathrm{in} \mathrm{the} \mathrm{kidney} \mathrm{resultantly} \mathrm{urine} \mathrm{become} \mathrm{alkaline.} \mathrm{It} \mathrm{is}$ associated with increased calcium and decreased potassium excretion, the higher excretion of calcium in alkaline urine tends to form calciferous stones with phosphates.

Some patient with nephrocalcinosis could not secrete highly acidic urine when challenged with an oral load dose 100 $\mathrm{mg} / \mathrm{kg}$ body weight is given. Short $\mathrm{NH}_{4} \mathrm{CL}$ loading test did not induce hypercalcemia in normal subject, but produce profound hypercalcemia in stone former patient suffering from HPT. RTA defect in stone formation produce chronic metabolic acidosis is associated with reduced renal tubular reabsorption of calcium result in hypercalciuria (Parfitt et al 19741).

\section{The Present Project was Undertaken}

a. To examine the usefulness of different doses of $\mathrm{NH}_{4} \mathrm{CL}[75$ and $150 \mathrm{mg} / \mathrm{kg}$ body weight] for the assessment of H.P.T. and renal tubular acidification status.

b. To investigate the involvement of hyperparathyroidism in stone formers of this region.

c. To investigate the involvement of renal tubular acidification defect in stone formers of this region. 


\section{MATERIAL AND METHODS}

The present study was planned with the following two objectives in view (a) To study the incidence of Renal Tubular Acidification (RTA) defects and Hyperparathyroidism (HPT) in the local stone formers by using the short ammonium chloride loading test; and (b) To establish the adequate dose of ammonium chloride for the test.
40 radiologically proved cases of upper urinary tract stone disease (SF) and 20 healthy and Normal Subjects (NS) formed the case material for the study. Including male and female of 13 to 60 years and all kept on normal diet.

\begin{tabular}{|c|c|c|c|c|c|}
\hline Sl. No. & Nature of Subjects & Range & Mean & SD+- & SE \\
\hline 1 & $\begin{array}{c}\text { Normal Subjects } \\
\text { No. 20 }\end{array}$ & $16-15$ Years & 36.75 & 13.43 & 3.89 \\
\hline \multirow{2}{*}{$\begin{array}{c}\text { Stone } \\
\text { Fale 32 } \\
\text { Female 8 }\end{array}$} & $\begin{array}{l}12-60 \text { Years } \\
14-30 \text { Years }\end{array}$ & 34.76 & 14.11 & 2.82 \\
\hline
\end{tabular}

$2 \mathrm{gm}$ and $1 \mathrm{gm}$ of elemental calcium (Ostocalcium) orally given on $2^{\text {nd }}$ and $3^{\text {rd }}$ days, the 24 hours urine sample collected on all three days and labelled as I, II and III. The three twenty four hours samples were analysed for calcium, inorganic phosphorus and creatinine and the values were calculated in the form of $\mathrm{mg} \%, \mathrm{mg} / 24$ hours, $\mathrm{mg} / \mathrm{gm}$ of creatinine and $\mathrm{mg} / \mathrm{m}^{2}$ of BSA.

\section{OBSERVATIONS}

\begin{tabular}{|c|c|c|c|c|c|}
\hline Sample No. & 24 Hours & mg\% & mg/24 Hours & mg/gm of Creatinine & mg/sq. m. BSA \\
\hline \multirow{2}{*}{ 1 First Day } & Range & $2.85-19.0$ & $31.3-323.0$ & $77.3-353.4$ & $21.18-219.1$ \\
Normal Diet & Mean & 10.5 & 155.2 & 195.0 & 103.0 \\
& SD+ - & 4.33 & 87.8 & 91.2 & 54.55 \\
\hline \multirow{2}{*}{ 2 Second Day Normal } & Range & $2.50-30.9$ & $43.5-361.8$ & $90.4-1208$ & $32.2-247.0$ \\
Diet + 2 gm Calcium & Mean & 13.28 & 176.0 & 353.2 & 115.81 \\
& SD & 7.96 & 101.75 & 299.4 & 66.57 \\
\hline \multirow{2}{*}{ 3 Third Day Normal } & Range & $2.7-31.4$ & $51.7-318.4$ & $110.3-416.6$ & $46.1-218.0$ \\
Diet + 1 gm Calcium & Mean & 12.67 & 164.35 & 255.2 & 106.46 \\
& SD & 8.51 & 90.3 & 104.0 & 54.33 \\
\hline
\end{tabular}

\begin{tabular}{|c|c|c|c|c|c|}
\hline Sample No. & 24 Hours & $\mathbf{m g} \%$ & $\mathbf{m g} / \mathbf{2 4}$ Hours & $\begin{array}{c}\mathbf{m g} \text { /gm of } \\
\text { Creatinine }\end{array}$ & mg/sq. m. BSA \\
\hline \multirow{2}{*}{ 1 First Day } & Range & $3.3-18.1$ & $29.9-231.2$ & $26.6-385.3$ & $17.2-127.8$ \\
Normal Diet & Mean & 8.73 & 103.8 & 167.33 & 69.96 \\
& SD & 4.19 & 57.9 & 88.94 & 37.08 \\
\hline \multirow{2}{*}{ 2 Second Day Normal } & Range & $2.5-22.5$ & $33.75-302.5$ & $57.7-503$ & $22.5-213.4$ \\
Diet + 2 gm Calcium & Mean & 9.36 & 148.2 & 240.1 & 97.8 \\
& SD & 4.8 & 85.2 & 118.5 & 56.6 \\
\hline \multirow{2}{*}{ 3 Third Day N.D. } & Range & $2.5-19.0$ & $30.8-337.0$ & $56.4-528.0$ & $22.3-189.3$ \\
+ 1 gm Calcium & Mean & 9.8 & 138.3 & 221.55 & 92.0 \\
& SD & 5.25 & 57.1 & 102.77 & 47.14 \\
\hline \multicolumn{7}{|r|}{ Table 3: 24-Hour Urinary Excretion of Calcium in Stone Formers on Normal Diet and with Calcium Supplementation } \\
\hline
\end{tabular}

\begin{tabular}{|c|c|c|}
\hline Value & “t” & P \\
\hline $\mathrm{mg} \%$ & 1019023 & $<0.02$ \\
\hline $\mathrm{mg} / 24$ Hours & 2.12578 & NS (Not Significant) \\
\hline $\mathrm{mg} / \mathrm{gm}$ Creatinine & 0.87887 & $<.01$ \\
\hline $\mathrm{mg} / \mathrm{m} 2$ BSA & 2.709 & Table 4: Comparison of Urinary Calcium Excretion on First 24 Hours \\
\hline \multicolumn{2}{|c|}{ Urine Sample in Normal Subjects and Stone Formers by Unpaired “" Test } \\
\hline
\end{tabular}

\begin{tabular}{|c|c|c|}
\hline Subjects & Mean Rise After 2 gm Calcium Loading & Mean Rise After 1 gm Calcium Loading \\
\hline Normal Subjects (N=20) & $10.0 \mathrm{mg}$ & $9.1 \mathrm{mg}$ \\
\hline Stone Formers (N=40) & $45.0 \mathrm{mg}$ & $34.5 \mathrm{mg}$ \\
\hline \multicolumn{2}{|c|}{ Table 5: Mean Rise in Urinary Calcium Excretion on Normal Diet and Calcium Supplementation } \\
\hline
\end{tabular}


1. $\mathrm{NH}_{4} \mathrm{CL}$ test was carried out on $4^{\text {th }}$ day, $75 \mathrm{mg} / \mathrm{kg}$ body weight group B and $150 \mathrm{mg} / \mathrm{kg}$ body weight group A given orally in capsule form at breakfast.

2. Hourly urine samples were collected separately over the next seven hours. Each sample was analysed for volume, $\mathrm{pH}$, Calcium (mg \%), Inorganic phosphorus (mg \%), Creatinine (mg \%), Titrable acidity (mg \%) and Titrable ammonia (mg \%). Observations were tabulated and subjected to statistical evaluation using paired ' $\mathrm{t}$ ' test.

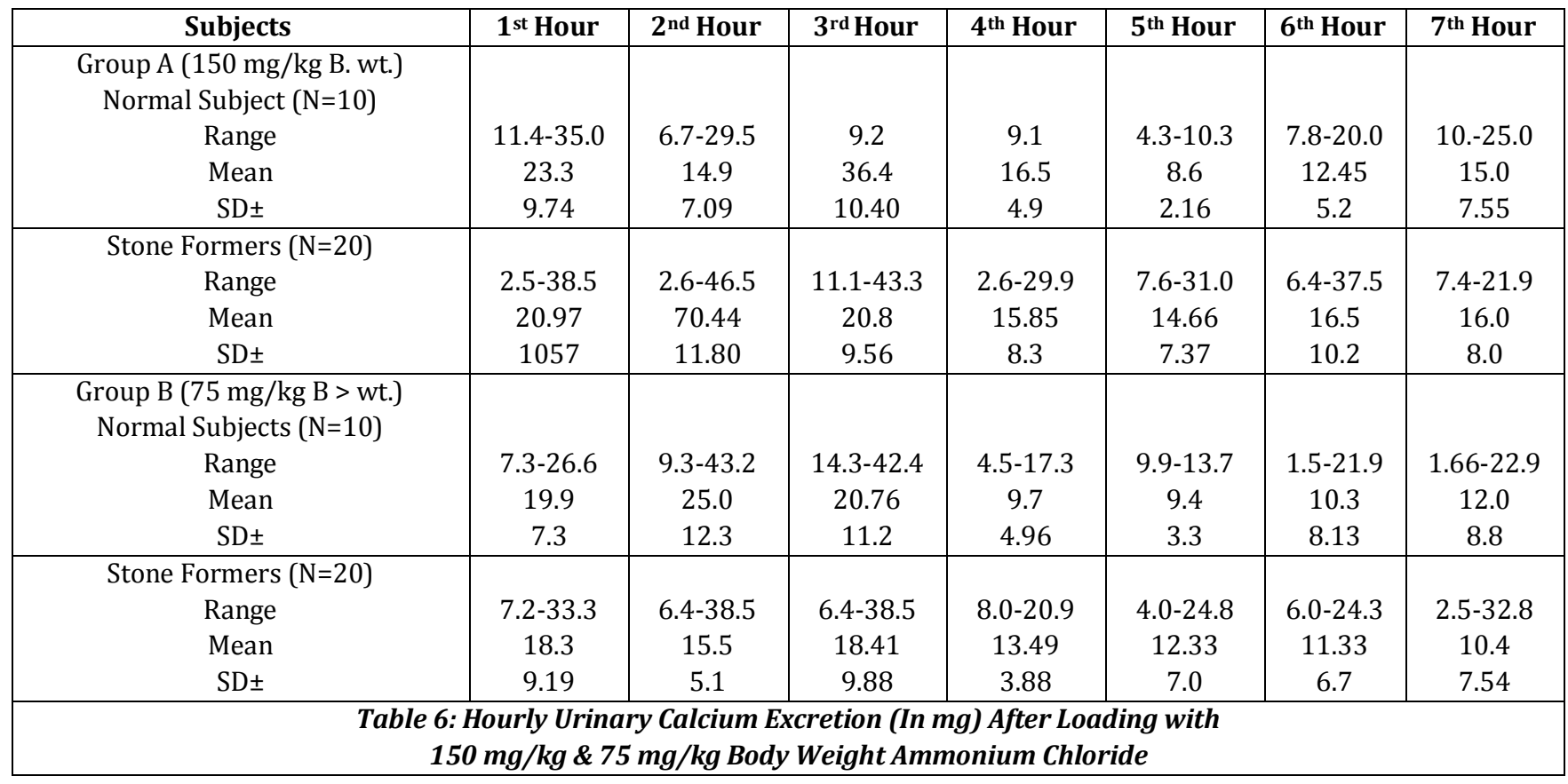

Twenty four hours urinary calcium excretion in normal subject as well as in stone former was within normal range $-200 \mathrm{mg} / 24$ hours, though it was slightly higher in the former $(155.2 \pm 87.8 \mathrm{mg} / 24$ hours).

In stone formers $(103.8 \pm 57.9 \mathrm{mg} / 24$ hours) finding of hypercalciuria is not an important risk. The stone former showed much higher absorption and excretion of calcium as compared with normal subject. The mean rise in 24 hours urinary calcium excretion after 2 gm calcium supplementation was $45.0 \mathrm{mg}$ and $10.8 \mathrm{mg}$ respectively, while on $1 \mathrm{gm}$ calcium $34.5 \mathrm{mg}$ in stone former and 9.5 $\mathrm{mg}$ in normal subject this four-fold difference in the absorption of calcium in stone former as compare to normal subject is an important figure brought out by this study and requires further evolution.

Ammonium chloride loading causes increased urinary calcium excretion in stone former as well as in normal subject no significant difference was observed and did not show any evidence of hyperparathyroidism in the subjects investigated.

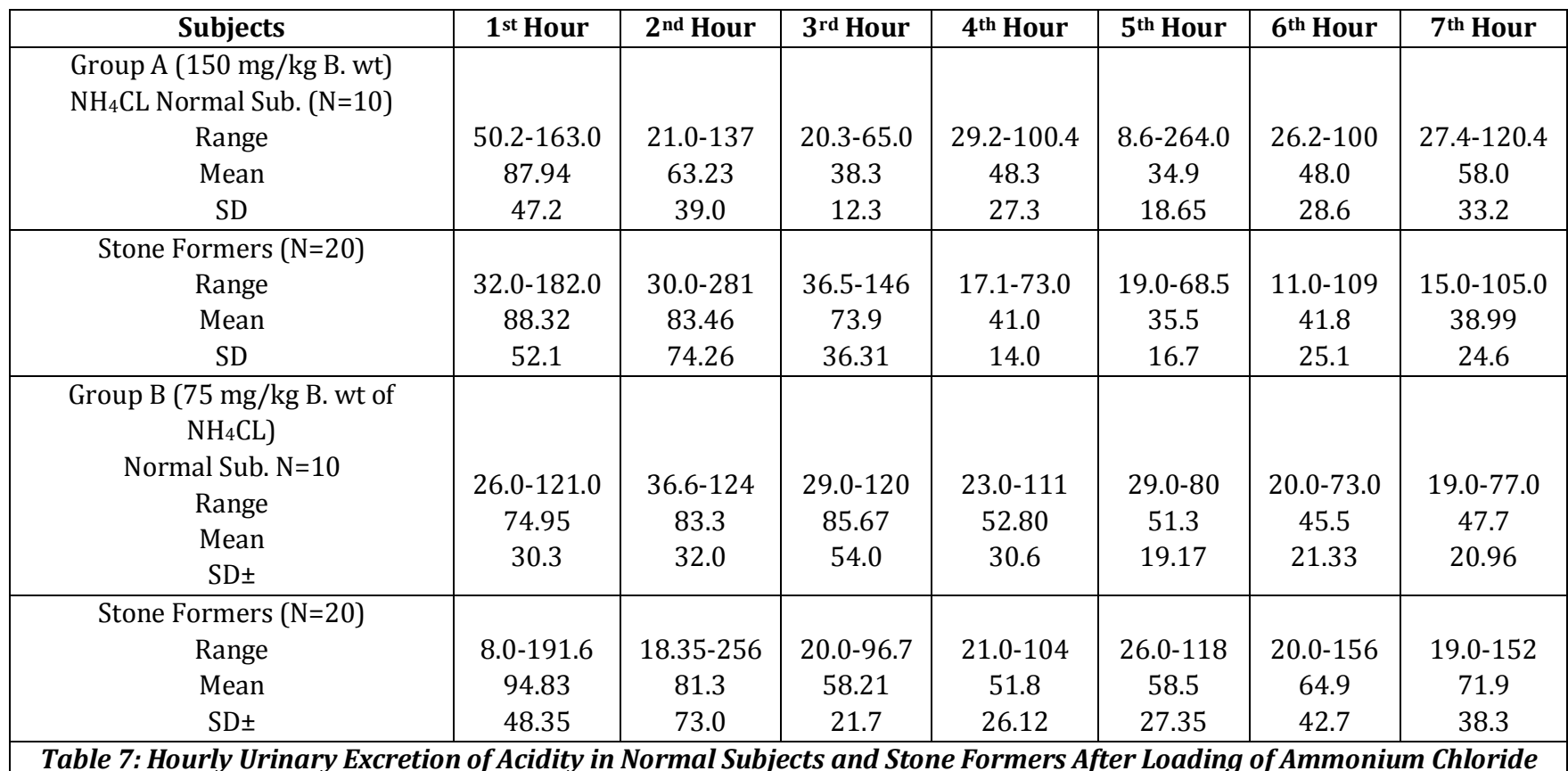

Statistically evaluation of hourly excretion of inorganic phosphorus between normal subject and stone formers was significantly lower in stone former in second and fourth sample and was noted in group A (150 mg/kg body weight) of $\mathrm{NH}_{4} \mathrm{CL}$. 
The hourly urinary ammonia excretion after ammonium chloride loading was two times higher in stone former as compared to normal subject in group A, but was not in group B. The difference of $(p<0.05)$ was observed in III urinary samples in group B.

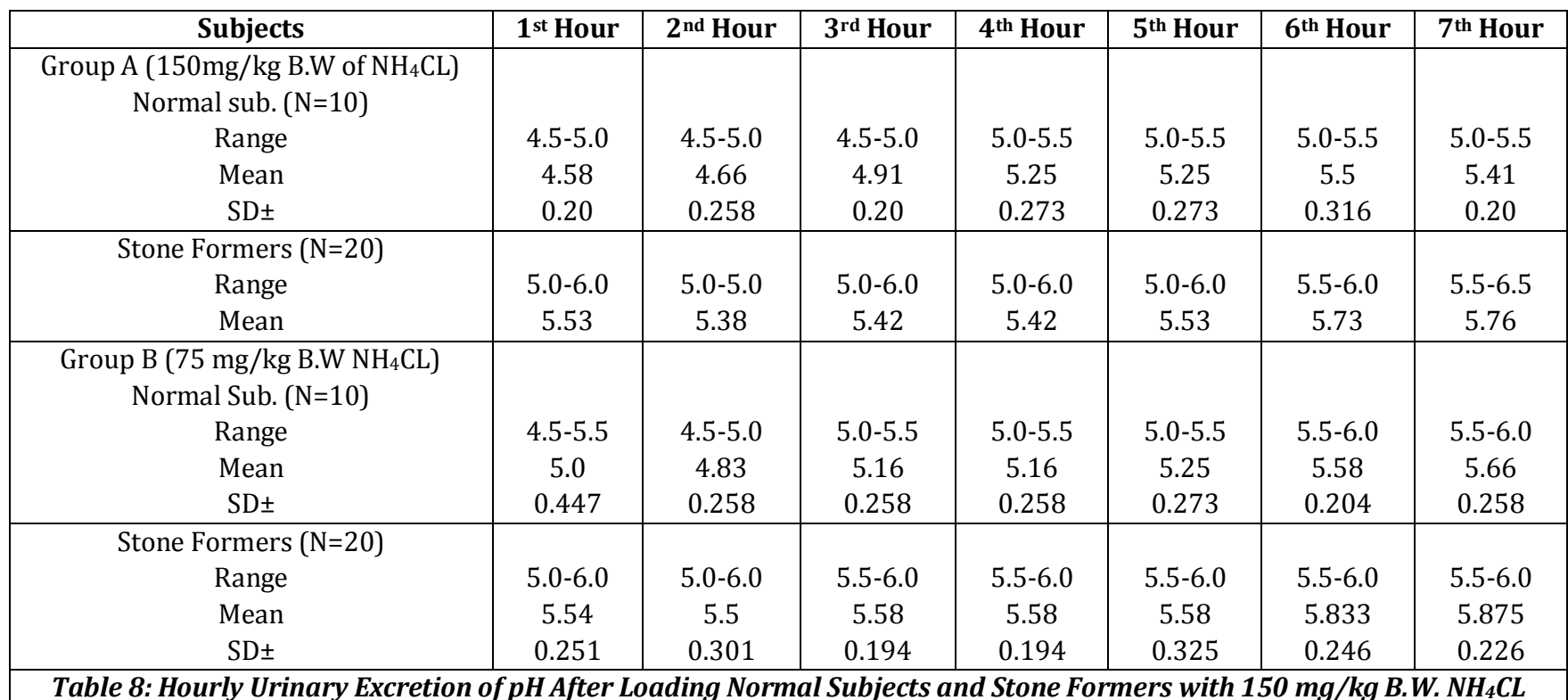

The ability to bring down the $\mathrm{pH}$ of urine up to 4.5 is the criteria on which the adequacy of renal tubular acidification is judged. Failure to achieve this indicates RTA defect.

\begin{tabular}{|c|c|c|c|}
\hline Group \& No. of Case & pH 4.5 & pH Between 4.5-5 & pH Above 5 \\
\hline Group A (150 mg/kg B.W. of $\left.\mathrm{NH}_{4} \mathrm{CL}\right)$ & Nil & $\mathrm{Nil}$ \\
Normal Sub. (N=20) Stone former $(\mathrm{N}=40)$ & $\mathrm{Nil}$ & $6(46.15 \%)$ & $7(53.8 \%)$ \\
\hline Group B (75 mg/kg mg/kg B.W. of $\left.\mathrm{NH}_{4} \mathrm{CL}\right)$ & & $\mathrm{Nil}$ \\
Normal Sub. (N=20) & $3(50.0 \%)$ & $3(50.0 \%)$ & $9(75.0 \%)$ \\
\hline Stone Former (N=40) & $\mathrm{Nil}$ & $3(25.0 \%)$ & \\
\hline
\end{tabular}

\begin{tabular}{|c|c|c|c|c|c|c|c|c|c|c|c|c|c|c|}
\hline Parameter & $1^{\text {st }} \mathbf{H}$ & Iour & $2^{\text {nd }} H$ & lour & $3^{\text {rd } H}$ & our & $4^{\text {th }} \mathrm{Hc}$ & our & $5^{\text {th }} \mathbf{H}$ & ur & $6^{\text {th }} \mathrm{Ho}$ & & $7^{\text {th }} \mathrm{H}$ & our \\
\hline & $\mathbf{t}$ & $\mathbf{p}$ & $\mathbf{t}$ & $\mathbf{p}$ & & & $\mathbf{t}$ & p & $\mathbf{t}$ & $\mathbf{p}$ & $\mathbf{t}$ & $\mathbf{p}$ & $\mathbf{t}$ & p \\
\hline $\mathrm{pH}$ & -6.640 & $<0.001$ & -6.311 & $<0.01$ & -2.921 & $<0.01$ & -1.151 & NS & -1.848 & NS & -1.792 & NS & -1.848 & NS \\
\hline Acidity & -0.015 & NS & -0.499 & NS & 2.322 & $<0.05$ & 0.782 & NS & -0.070 & NS & 0.479 & NS & 1.405 & NS \\
\hline Ammonia & -2.8028 & $<0.02$ & -1.3392 & NS & -2.520 & $<0.05$ & -1.6297 & NS & -2.6722 & $<0.02$ & -1.6877 & NS & -2.2512 & $<0.05$ \\
\hline Calcium & 0.4569 & NS & -0.484 & NS & -1.143 & NS & 0.176 & NS & -1.948 & NS & -0.909 & NS & 0.05 & NS \\
\hline Phosphorus & 0.70 & NS & -2.619 & $<0.02$ & 1.106 & NS & 2.44 & $<0.05$ & 0.65 & NS & 1.281 & NS & 1.0447 & NS \\
\hline
\end{tabular}

\section{DISCUSSION}

Urinary calculus is well known from ancient times and prevalent in several pockets of India including Rajasthan in Udaipur, 56 urinary stone patients per 10000 hospital admissions. ${ }^{[2]}$ Among stone formers a large number of recurrent stone formers are also present, ${ }^{[3]}$ many intrinsic and extrinsic factors operate. A sizable group of stone formers classified as "idiopathic stone formers." In our country renal tubular acidosis and subclinical PTH are two such conditions, which may cause stone episode or recurrence. Short ammonium chloride loading test is good to ascertain HPT status and also good to diagnose renal tubular acidification defect.[4]

Some nephrocalcinosis patient could not secrete highly acidic urine when challenged with $100 \mathrm{mg} / \mathrm{kg}$ body wt. of $\mathrm{NH}_{4} \mathrm{CL}$ loading dose and did not induce hypercalcemia in normal subject, but produce profound hypercalcemia in SF with HPT. In RTA defect reduces reabsorption of calcium result in hypercalciuria.[1]

Wrong and Davies[5] suggested a short ammonium chloride test to ascertain the renal acidification status of the kidney; unfortunately has not been used in Indian population. The present study is an effort made in this direction. The mechanism of induction of metabolic acidosis by $\mathrm{NH}_{4} \mathrm{CL}$ is very simple; after absorption $\mathrm{NH}_{4} \mathrm{CL}$ reaches to liver where ammonia is split off and converted to urea leaving HCL. The disposable of this excess acid $[\mathrm{H}+]$ is the function of kidney, so as to maintain the subtle acid-base balance in the blood. The kidneys with renal acidification defect show a different degree of failure to excrete the excess load of acid from the body. Normal person within 2 to 3 hours to excrete acidic urine $\mathrm{pH}$ below 5 , usually 4.5 . In the incomplete renal tubular acidosis kidney is unable to acidify urine to a $\mathrm{pH}$ lower than 5.0, wherein direct/complete renal tubular acidosis kidney has 
very little capacity for acidification with result that alkaline urine is excreted. Turning to renal handling of calcium $50-55 \%$ of glomerular filtration of calcium is reabsorbed by proximal convoluted tubules, $20-25 \%$ by loop of Henle and $20 \%$ by distal convoluted tubules. Parathormone increases the absorption of calcium from intestine, reabsorption from bones and kidney and maintains normal ionic calcium in the blood. In HPT cases reabsorption increases the ionic calcium in the blood. The high ionic calcium causes distal renal acidification defect and leads to hypercalciuria,' that is renal tubular acidosis and hyperparathyroidism can concomitantly be tested by acid load with adequate body calcium status. This forms the basis of short ammonium chloride loading test with preload of calcium. This preload of calcium causes profound hypercalciuria in stone patient with HPT, which is absent in normal subject. [6,7,8,9]

$\mathrm{NH}_{4} \mathrm{CL}$ is a gastric irritant, so its proper dose is also standardised.

PYRAH[10] used $100 \mathrm{mg} / \mathrm{kg}$ body wt. of $\mathrm{NH}_{4} \mathrm{CL}$ and Danielson et al[8] administered NH4CL orally in dose $17.5 \mathrm{gm}$ irrespective of the body wt. in 586 patients [S.F.] and 47 in normal subject. She observed $20 \%$ of S.F. having tubular acidification defect. [b] All the N.S. excrete acidic urine $\mathrm{pH} 5.0$ [even up to $\mathrm{pH}$ 4.5]. [c] Patients suffering from incomplete renal tubular acidosis excrete acidic urine up to $\mathrm{pH} 5.0$ only. [d] Pt. with renal tubular acidosis type 2nd [Complete RTA] could not acidify urine and excreted alkaline urine [pH more than 7.0]. The pt. with complete and incomplete RTA had more severe stone disease that idiopathic stone formers.

Alken et al[9] done the same test and found pronounced hypercalciuria in HPT patients. As stated in materials and methods, the 4 days protocol as suggested by Alken et al[9] was followed with $\mathrm{NH}_{4} \mathrm{CL}$ dose $150 \mathrm{mg} / \mathrm{kg}$ in group [a] and 75 $\mathrm{mg} / \mathrm{kg}$ in group [b] instead of $165 \mathrm{mg} / \mathrm{kg}$ body wt. was given and addition was the collection of 24 hours urine sample on the days of calcium supplementation. The data of calcium excretion in N.S. and SF presented in Table 2 and 3. The statistical evaluation is given in Table 5 and 6 . The 20 normal subjects excreted slightly larger quantity of calcium [155.2+87.8] as compared to S.F. [103.8+57.9 mg/24 hours] with a notable mean rise of calcium level after $1 \mathrm{gm}$ calcium loading. The mean rise $9.1 \mathrm{mg}$ in NS and in SF it was 4 times high [ $34.5 \mathrm{mg}$ ] and $2 \mathrm{gm} 45.0 \mathrm{mg}$ in SF and in NS $10.8 \mathrm{mg}$. This data emphasises the fact that SF have enhanced capacity to absorb calcium from intestine than controls [HPT, poor production of 125-dihydroxycholecalciferol; primary hypercalciuria or renal leak]. In Table 9 and 10 on urinary $\mathrm{pH}$, ammonia and titrable acidity. All NS acidify urine up to $\mathrm{pH} 4.5$ with $150 \mathrm{mg}$ body $\mathrm{NH}_{4} \mathrm{CL}$ dose, wherein stone formers $46.2 \%$ could acidify the urine between 4.6 to 5.0 and 53.8 and could not acidify urine below $\mathrm{pH}$ 5.0. Members from neither of group excreted alkaline urine.

When all data are considered together, it can be concluded that [1] $150 \mathrm{mg} / \mathrm{kg}$ body wt. of $\mathrm{NH}_{4} \mathrm{CL}$ is sufficient to evaluate the renal acidification defect; [2] $75 \mathrm{mg} / \mathrm{kg}$ body wt. $\mathrm{NH}_{4} \mathrm{CL}$ is inadequate to evaluate the renal acidification defect; [3] Stone former absorbed relatively larger dietary calcium than NS. [4] HPT did not appear to be an aetiological factor in any of the stone formers; [5] 53.8\% of stone formers appear to have incomplete renal tubular acidification defect. [6] Short ammonium chloride loading test is a reliable adjuvant to evaluate parathyroid and renal acidification defect.

\section{SUMMARY AND CONCLUSION}

1. Incomplete R.T.A. defect was present in $53.8 \%$ of stone formers investigated.

2. Complete R.T.A. defect was not present in any of the stone formers.

3. Hyperparathyroidism was not present in any of the subjects. It denotes HPT cases are not present in this region [Udaipur - Rajasthan].

4. Short ammonium chloride loading test is a reliable tool to evaluate the presence of Hyperparathyroidism and Renal Tubular Acidification Defect.

5. For a reliable test, ammonium chloride has to be given in the dose of $150 \mathrm{mg} / \mathrm{kg}$ body weight.

6. Hypercalciuria is not a feature amongst the local the local population in both stone formers and in normal subjects.

7. The stone formers show higher absorption and excretion of calcium on oral supplementation of calcium as compared to normal subjects.

\section{REFERENCES}

1. Parfitt AM. Investigation of disorder of the parathyroid glands. Clin Endocrinol Metab 1974;3(3):451-74.

2. Pendse AK, Srivastava AK, Kumawat JL, et al. Urolithiasis in Udaipur, Rajsthan. J IMA 1984;82(5):151-5.

3. Pendse AK, Srivastava AK, Kumawat JL, et al. Chemical composition of stones and urinary profile of stone formers in Udaipur. Bull Int Cong Surg 1986: 188.

4. Smith LH. Renal tubular acidosis in metabolic basic of inherited diseases. In: Wyngarden JB, Fredrickson DS. eds. New York: McGraw-Hill 1960.

5. Wrong 0, Davies HEF. The excretion of acid in renal disease. Quart J Med 1959;28(110):259-313.

6. Coe FL, Firpo JJ, Hollandsworth DL, et al. Effect of acute and chronic metabolic acidosis on serum immunoreactive parathyroid hormone in man. Kidney Int 1975;8(4): 263-73.

7. Backman U. Kidney function in recurrent renal stone formers. Scand J Urol Nephrol 1976;(Suppl 35):1-90.

8. Danielson BG, Backman U, Fellstorm B, et al. Exprence with the short NH4Cl test. In: Smith LH, Robertson WG, Finlayson B. eds. Urolithiasis. New York: Springer US 1981:71-6.

9. Peter A. Short Ammonium Chloride loading test far evaluation of hyperparathyroidism. Urolithysis. In: Smith LH, Robertson WG, Finlayson B. eds. Clinical \& basic research. New York: Springer US 1981:93-7.

10. Pyrah LN. Renal calculus. Berlin Heidelberg, New York: Springer Verlag 1979:78-83. 